\title{
LSD1 Inhibitor IMG-7289
}

National Cancer Institute

\section{Source}

National Cancer Institute. LSD1 Inhibitor IMG-7289. NCI Thesaurus. Code C131827.

An orally available, irreversible inhibitor of lysine-specific demethylase 1 (LSD1), with potential antineoplastic activity. Upon administration, IMG-7289 binds to and inhibits LSD1, a demethylase that suppresses the expression of target genes by converting the di- and mono-methylated forms of lysine at position 4 of histone $\mathrm{H} 3(\mathrm{H} 3 \mathrm{~K} 4)$ to monoand unmethylated H3K4. LSD1 inhibition enhances H3K4 methylation and increases the expression of tumor suppressor genes. In addition, LSD1 demethylates mono- or dimethylated H3K9 which increases gene expression of tumor promoting genes; thus, inhibition of LSD1 also promotes H3K9 methylation and decreases transcription of these genes. Altogether, this may lead to an inhibition of cell growth in LSD1-overexpressing tumor cells. LSD1, an enzyme belonging to the flavin adenine dinucleotide (FAD)dependent amine oxidase family is overexpressed in certain tumor cells and plays a key role in the regulation of gene expression, tumor cell growth and survival. 